\title{
Submitted: $\quad$ Renal echotextural changes in Nigerian workers chronically Accepted: exposed to petroleum-based liquid fuels
} 09.01.2020

Published: 31.03.2020

\author{
Keywords \\ renal echotextural \\ changes, \\ ultrasound, \\ exposure, \\ petroleum-based \\ liquid fuels
}

\author{
Angel-Mary C. Anakwue', Felicitas U. Idigo', Raphael C. Anakwue ${ }^{2}$ \\ ${ }^{1}$ Department of Medical Radiography and Radiological Sciences University of Nigeria Enugu \\ Campus, Enugu State, Nigeria \\ ${ }^{2}$ Department of Medicine, University of Nigeria Ituku/Ozalla Enugu, Enugu State, Nigeria \\ Correspondence: Dr Anakwue, Angel-Mary Chukwunyelu, Department of Medical Radiography \\ and Radiological Sciences University of Nigeria Enugu Campus, Nigeria; tel.: +2348035495528, \\ e-mail: angel-mary.anakwue@unn.edu.ng
}

DOI: $10.15557 /$ JoU.2020.0004

\begin{abstract}
Background: Exposure to hydrocarbon is associated with an increased risk of development of chronic kidney disease. Ultrasound, which is a non-invasive imaging modality, provides very important information about kidney morphology. Objective: The aim of this study was to evaluate the effects of chronic exposure to some petroleum products on the kidney of exposed workers using sonography. Materials and methods: This was a prospective cross-sectional study involving 415 workers with chronic workplace exposure to petroleum fuel in Enugu metropolis. The study population comprised 164 petrol station attendants, 175 automobile mechanics and 76 petrol tanker drivers aged between 20 and 65 years. Abdominal ultrasound was performed, as well as serum urea and creatinine were measured to assess the kidneys of these workers chronically exposed to petroleum fuels, and the findings were compared to findings in an aged-matched, non-exposed control group. Results: Increased echogenicity of the kidneys was observed in 21 subjects from the study group and this differed significantly $(p<0.05)$ from the findings in the control group. Conclusions: The study has shown that chronic exposure to petroleum fuel affects renal echotexture and that ultrasound may serve as a useful non-invasive tool for routine use in the assessment of petroleum-induced nephropathy.
\end{abstract}

\section{Introduction}

Crude petroleum may be distilled into such fractions as diesel, gasoline, kerosene, heavy gas oils, lubricating oils, as well as residual and heavy fuels. Diesel, gasoline and kerosene are among the frequently used fractionated products of crude petroleum and are called petroleumbased liquid fuel ${ }^{(1)}$. These products are basically composed of aliphatic, aromatic and a variety of other branched saturated and unsaturated hydrocarbons at variable proportions $^{(2)}$.

Like other xenobiotics, these hydrocarbon products are converted in the body into different reactive metabolites, which interact with various tissues, especially the metabolizing, distributing and excreting tissues, exerting toxic effects on them. The kidneys are excreting organs that could be damaged by hydrocarbons. Indeed Uboh et al. ${ }^{(3)}$ has shown that interaction of the hydrocarbon with renal tissues may cause cellular injury.

Exposure to hydrocarbon (HC) is associated with an increased risk of developing chronic kidney disease (glomerular diseases in particular). There are several studies that have demonstrated hydrocarbon-induced kidney toxicity $^{(4-10)}$.

Ishola et al. (10) studied the association of hydrocarbon exposure with glomerulonephritis (GN) in Nigerians. Their findings suggest that $\mathrm{HC}$ exposure is a significant 
risk factor for GN in Nigerians with chronic renal failure (CRF). These findings are of great importance given the widespread use and abuse of petroleum products in Nigeria $^{(11)}$.

Ultrasound is employed in the clinical examination of the kidneys. It provides very important information about kidney morphology and has become the standard imaging modality in the investigation of kidneys as it displays excellent anatomic detail, and most of the reno-parenchymatous diseases are easily discernible ${ }^{(12,13)}$.

There is paucity of literature on the use of sonography in the assessment of organ toxicity in workers exposed to petroleum fuel. To the best of our knowledge, no assessment of sonographic kidney changes was performed in this group of workers in Nigeria despite the fact that they handle these products without proper protection against possible toxic effects. There is increasing prevalence of kidney diseases in Nigeria and worldwide, and the etiology is not completely known ${ }^{(10)}$. Kidney diseases also cause hypertension, but only in $5-10 \%$ of the cases is the cause of the raised blood pressure known. This work was therefore designed to assess the toxicological effects of chronic exposure to petroleum based liquid fuel on the kidneys using sonography, hoping that the tool will be useful in unraveling the unknown causes of kidney diseases and hypertension in Nigeria.

\section{Materials and methods}

This study was conducted in Enugu, the capital city of Enugu State in Southeast Nigeria. A cross-sectional design was adopted and the sample size was 415 subjects. The study population included 164 petrol station attendants, 175 automobile mechanics and 76 petrol tanker drivers aged between 20 and 65 years, who gave consent to participate in the study. These subjects have been on the job for 5 years and more. The control group included 415 age- matched volunteers. These controls were apparently healthy subjects, who were not involved in activities predisposing them to serious contact with petroleum distillates or solvents of any kind, and have been on their job for at least 5 years. This group was recruited among shop attendants and traders in Ogbete and Kenyatta markets in Enugu metropolis. All participants were males and of Nigerian origin.

The study was approved by the Ethics committee of the University of Nigeria Teaching Hospital Enugu and all participants gave a written informed consent to participate in the study. A questionnaire was used to collect data on, among other things, age, socio-economic status, health status, and duration of work. The weight of each participant was measured using an analog scale, and their height was measured using a portable stadiometer. These data were used to calculate the Body Mass Index (BMI).
The exclusion criteria for the study included:

1. Chronic alcoholism which $\mathrm{Elia}^{(14)}$ defined as intake of more than 3 units (i.e. $1 \frac{1 / 2}{2}$ bottles) daily for males ( 1 unit of alcohol $=8$ grams);

2. Raised blood pressure (hypertension) defined as blood pressure of $140 / 90 \mathrm{mmHg}^{(15)}$ prior to exposure to petroleum products;

3. Diabetes mellitus defined as blood sugar level above $126 \mathrm{mg} / \mathrm{dL}$ (fasting plasma glucose) or $2 \mathrm{Hr}$ plasma glucose $\geq 200 \mathrm{mg} / \mathrm{dL}^{(16)}$ prior to exposure to petroleum products;

4. Abuse of illicit drugs;

5. Cigarette smoking in the past three months;

6. Recent use of herbal drugs;

7. Positive HIV I and II Serology;

8. Obesity defined as BMI $>30 \mathrm{~kg} / \mathrm{m}^{2}$ in males ${ }^{(14)}$.

Real-time gray-scale ultrasound of the kidneys was performed using Siemens Sonoline LX unit with a 3.5 MHz curvilinear transducer to assess renal echogenicity. Standard technique for scanning the kidney was followed as described by previous authors ${ }^{(17,18)}$. All subjects were fasting for 6 hours before the examination.

The right kidney was assessed according to the standards described by Sanders et al. ${ }^{(17)}$ and Palmer ${ }^{(18)}$ with the participants in the supine position, using the liver as an acoustic window, and scanning longitudinally over the right abdomen. Coronal and lateral approaches were sometimes used. It was necessary to rotate the participants in the left lateral decubitus position, scanning through the psoas muscle to enhance visualization, especially when bowel gas was present. The same sequence was used in assessing the left kidney. Fluid in the stomach following oral intake of water provided acoustic window when bowel gas became problematic. Suspended deep inspiration was usually necessary.

Kidney size, parenchymal echogenicity, central echo complex and ancillary abnormalities were evaluated.

Using these parameters, the presence of generalized parenchymal disease was identified. Ultrasonographic findings were then analyzed according to the following classification:

Grade I (Mildly echogenic kidneys): Considered when the increase in parenchymal echogenicity is the same as the hepatic echogenicity. There is accentuation of cortical echoes and the pyramids remain normal with sinus-parenchymal differentiation.

Grade II (Moderate alteration): Considered when the echogenicity is greater than the hepatic parenchyma but less than the central echo complex resulting in the accentuation of cortical echoes with moderate loss of sinus-parenchymal differentiation.

Grade III (Marked alteration): Considered when the parenchymal echogenicity is equal to that of the central echo 
complex leading to generalized parenchymal abnormality with complete loss of sinoparenchymal differentiation.

When the hepatic echogenicity was altered, grading of nephropathy depended on sino-cortical echo relationship only.

For the renal function, blood was collected from the study participants by standard venopuncture technique and drawn into a tube which did not contain anticoagulant and clotting was allowed. The serum was then separated from the clot. Separated serum or plasma was not allowed to remain at room temperature longer than 8 hours. If assays were not completed within 8 hours, serum was stored at $2^{\circ} \mathrm{C}$ to $8^{\circ} \mathrm{C}$. Serum level of creatinine was determined using the Jaffe's reaction method (Cheesbrough, 1999) while urea was measured by the colorimetric method using a modified Berthelot reaction.

The data was recorded and analyzed using Statistical Package for Social Sciences (SPSS) version 20.0. The mean and standard deviation were calculated and unpaired t-test, Fisher's exact test and Chi squared were used at 5\% level of significance.

\section{Results}

The subjects were aged between 20 and 65 years with a mean age of 38 years for the exposed group and 37 years for controls, as shown in Tab. 1. The mean exposure duration was 11 years. The exposed and control groups were comparable in age, sex, height, weight, BMI, duration of exposure and all life style factors.

Table 2 shows renal echotextural findings in the study and control groups. Twentyone participants from the study group were
Tab. 1. Demographic characteristics of the study group vs controls

\begin{tabular}{|l|c|c|c|}
\hline Parameter & $\begin{array}{c}\text { Exposed } \\
\mathbf{N = 4 1 5}\end{array}$ & $\begin{array}{c}\text { Unexposed } \\
\mathbf{N = 4 1 5}\end{array}$ & $\begin{array}{c}\text { P-value of } \\
\text { unpaired t-test } \\
\text { at } \mathbf{0 . 0 5} \text { level } \\
\text { of significance }\end{array}$ \\
\hline Age (years) & $38 \pm 12$ & $37 \pm 11$ & 0.2420 \\
\hline $\begin{array}{l}\text { Exposure duration } \\
\text { (years) }\end{array}$ & $11 \pm 7.2$ & $11 \pm 7.2$ & 0.5025 \\
\hline Height (m) & $1.7 \pm 0.058$ & $1.7 \pm 0.053$ & 0.3312 \\
\hline Weight (kg) & $68 \pm 6.60$ & $68 \pm 5.90$ & 0.3470 \\
\hline BMI & $22.83 \pm 1.272$ & $22.69 \pm 1.199$ & 0.2289 \\
\hline
\end{tabular}

All values are means \pm SDs

Table 1 shows the characteristics of the study and control groups. The groups were similar in age, height, weight and body mass index. The $p$-value of unpaired t-test used to analyze the data showed no statistical difference at 0.05 level of significance.

Tab. 2. Kidney echogenicity in chronically exposed workers and comparison with their control

\begin{tabular}{|l|c|c|c|}
\hline Category & $\begin{array}{c}\text { Kidney } \\
\text { echogenicity } \\
\text { Normal }\end{array}$ & $\begin{array}{c}\text { Kidney } \\
\text { echogenicity } \\
\text { Abnormal }\end{array}$ & Total \\
\hline Exposed & 394 & 21 & 415 \\
\hline Unexposed & 410 & 5 & 415 \\
\hline Total & 804 & 26 & 830 \\
\hline
\end{tabular}

Fisher's test- significant, $a<0.05 ; p$-value $<0.0036^{* *}$.

This Table summarizes the effect of petrol on renal echogenicity in the exposed study subjects compared to unexposed controls. From the table, a higher prevalence of echotextural abnormalities was observed among the exposed vs the unexposed subjects.

Statistical analyses using Fisher's exact test revealed a significant difference at $a<0.05$ with a $p$-value of 0.0036 .

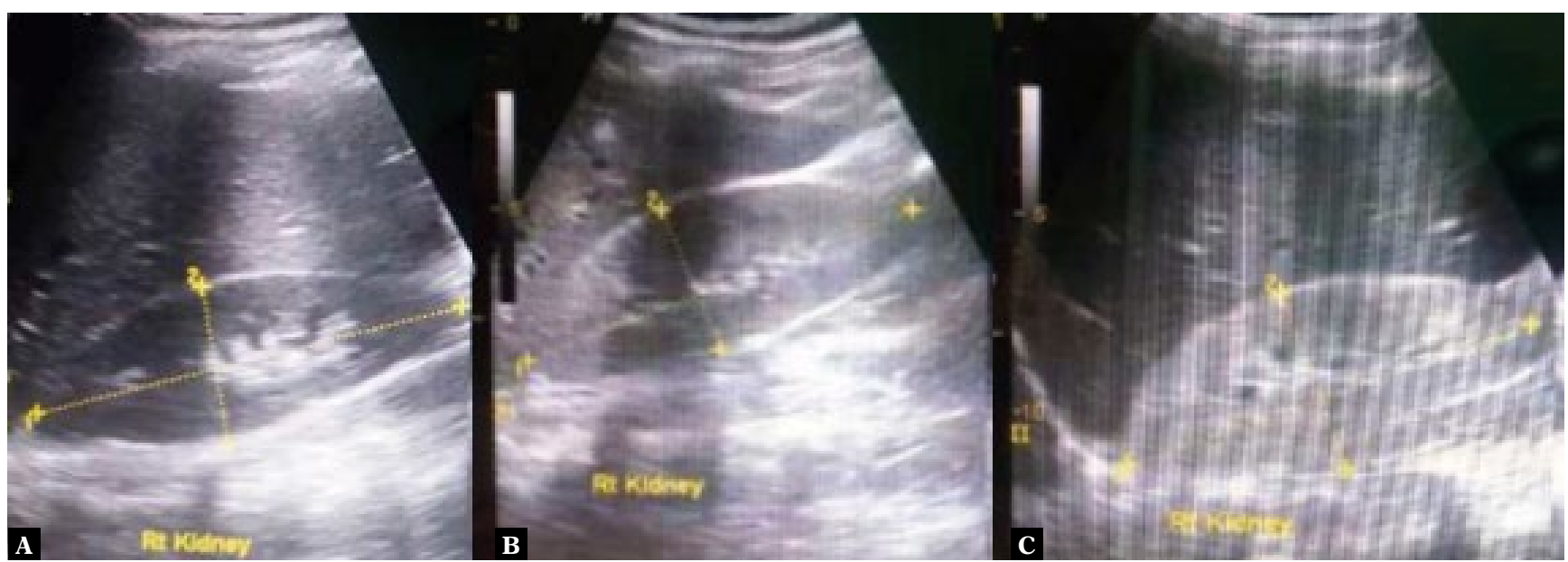

Fig. 1. Sonograms showing different renal echogenicity. A. Normal renal echogenicity with good sinoparenchymal differentiation. B. Mildly echogenic kidneys. The increase in parenchymal echogenicity is the same as the hepatic echogenicity. C. Marked alteration in echogenicity. Parenchymal echogenicity is almost equal to that of the central echo complex leading to generalized parenchymal abnormality with complete loss of sinoparenchymal differentiation 
Tab. 3. Degree of kidney echotextural alterations in the subjects vs controls

\begin{tabular}{|c|c|c|c|c|c|}
\hline Category & Normal echotexture & $\begin{array}{c}\text { Mild } \\
\text { alteration }\end{array}$ & $\begin{array}{l}\text { Moderate } \\
\text { alteration }\end{array}$ & $\begin{array}{c}\text { Marked } \\
\text { alteration }\end{array}$ & Total \\
\hline Exposed & 394 & 16 & 4 & 1 & 415 \\
\hline Unexposed & 410 & 5 & 0 & 0 & 415 \\
\hline Total & 804 & 21 & 4 & 1 & 830 \\
\hline
\end{tabular}

observed to have abnormal echotexture (Fig. 1). This differed significantly $(p<0.05)$ from the findings in the control group where abnormal kidney echotexture was observed in only 5 patients. The majority of alterations observed were mild in nature, as shown in Tab. 3 .

The mean urea and creatinine levels were significantly higher (unpaired t-test at 0.05 -level of significance) in the study group than in the control group (Tab. 4). These serum biochemical markers indicated nephropathy even though the values obtained did not exceed the reference level in any of the parameters studied.

\section{Discussion}

The kidneys play a vital role in the excretion of xenobiotics from the body, as well as participate in the homeostasis of acid-base, fluid and electrolyte in humans. This is achieved by excretion of waste products of metabolism (such as urea, creatinine and uric acid) and by specifically adjusting the urinary excretion of water and electrolytes to match the net intake and endogenous production ${ }^{(3)}$.

Occupational exposure and the associated health hazards have been a cause for concern for many researchers. Previous subchronic and/or chronic inhalation studies of unleaded gasoline and a variety of petroleum naphtha, solvents, and distillates have shown that these complex materials are capable of inducing a distinctive nephropathy ${ }^{(19)}$.

Although the association between hydrocarbon exposure and development of renal disease has been studied by many researchers, studies using sonography are very sparse.
Increased renal parenchymal echotexture suggestive of glomerulonephritis was the major sonographic abnormality seen in this study. We found a statistically significant difference $(p<0.05)$ in the echopattern of the subjects exposed to petroleum products compared to the unexposed controls. This is in agreement with the findings presented by Pranjic et al. ${ }^{(20)}$. In their work, 8 out of $37(21.62 \%)$ exposed workers were seen to have chronic kidney disease and this differed significantly $(p<0.05)$ from the findings in the unexposed controls. In this work however, only $21(5.06 \%)$ subjects had abnormal renal echotexture. These results show that exposure to gasoline vapours may be a predisposing factor for renal function impairment in chronically exposed workers. To our knowledge, no other study reported on the renal sonographic findings after chronic exposure to petrol.

Chronic exposure to pollutants of petroleum origin may cause glomerulonephritis as confirmed by the echotextural changes and elevated serum urea and creatinine observed in this study and in the works of other researchers. The observed alterations in the renal echotexture in the exposed workers may be due to the fact that the interaction of these reactive metabolites formed during the detoxification of petroleum products with renal tissues may have caused cellular and tissue damage ${ }^{(3)}$, which most likely led to the morphological changes seen. This should prompt clinicians to pay greater attention to patients' occupational exposures.

The results of the present study therefore strongly support previous epidemiological evidence suggesting that hydrocarbon exposure may induce glomerulonephritis and worsen its course in many patients ${ }^{(8,10)}$. The presence of renal echotextural changes observed in this study and its public health implications necessitate urgent intervention in Nigeria, especially

Tab. 4. Urea and creatinine levels in exposed workers vs controls

\begin{tabular}{|l|c|c|c|c|}
\hline Parameter & Exposed & Unexposed & Reference range & $\begin{array}{c}\text { P-value of unpaired t-test at } 0.05 \text { level } \\
\text { of significance }\end{array}$ \\
\hline Urea & $15 \pm 3.7$ & $12 \pm 3.8$ & $7-23 \mathrm{mg} / \mathrm{dL}$ & $<0.0001^{* * * *}$ \\
\hline Creatinine & $1.1 \pm 0.18$ & $0.93 \pm 0.15$ & $0.7-1.5 \mathrm{mg} / \mathrm{dL}$ & $<0.0001^{* * * * *}$ \\
\hline
\end{tabular}

This table summarizes the results of the renal tests. Mean urea and creatinine levels were significantly higher (unpaired t-test at 0.05 -level of significance) in the study group vs control group. These serum biochemical markers indicated nephropathy even though the values obtained did not exceed the reference level in any of the parameters studied. 
as altered liver echopattern and liver function was already reported in this group of workers ${ }^{(21)}$. This is so in consideration of the poor handling and abuse of petroleum products as therapeutic agents, the widespread lack of use of protective devices among petroleum workers, roadside hawking of fuel and the indiscriminate siting of petrol filling stations in Nigeria.

In view of this, there is need for education on the safe handling of this indispensable commodity to protect the health of those likely to be exposed to petroleum products. Also, there is need for regulating the location of petrol stations around residential areas and the use of gasoline vapour recovery device (GVRD) at filling stations, especially during dumping of fuel and car refueling.

This study reports a significant increase in blood urea and creatinine levels in the exposed workers compared to controls. These results show that exposure to gasoline vapours may be a predisposing factor for renal function impairment in chronically exposed workers. These findings are in agreement with the study of Nwanjo and Ojiako ${ }^{(22)}$. Bartimaeus and Jacobs ${ }^{(23)}$ also found that chronic exposure to petrol could cause considerable nephrotoxicity. Similar findings were also reported in experimental models ${ }^{(24)}$.

Though obtaining histological information was not considered in this study due to ethical issues, its availability would have enabled the correlation of the sonographic findings with biopsy findings. This was a limitation of this work.

\section{References}

1. Edwards T: Liquid fuels and propellants for aerospace propulsion: 1903-2003. J Propul Power 2003;19: 1089-1107.

2. Okoro AM, Ani EJ, Ibu JO, Akpogomeh BA: Effect of petroleum products inhalation on some haematological indices of fuel attendants in Calabar metropolis, Nigeria. Niger J Physiol Sci 2006; 21: 71-75.

3. Uboh F, Akpanabiatu M, Ekaidem I, Eteng M, Eyong E: Exposure to gasoline and kerosene vapours: a risk factor for nephrotoxicity in rats. IJTO 2009; 7.

4. Bell GM, Gordon AC, Lee P, Doig A, MacDonald MK, Thomson D et al.: Proliferative glomerulonephritis and exposure to organic solvents. Nephron 1985; 40: 161-165.

5. Zimmerman SW, Groehler K, Beirne GJ: Hydrocarbon exposure and chronic glomerulonephrities. Lancet 1975; 2: 199-201.

6. Yaqoob M, Bell GM, Percy DF, Finn R: Primary glomerulonephritis and hydrocarbon exposure: a case-control study and literature review. Q J Med 1992; 83: 409-418.

7. Yaqoob M, Bell GM, Stevenson A, Mason H, Percy DF: Renal impairment with chronic hydrocarbon exposure. Q J Med 1993; 86: 165-174.

8. Ravnskov U: Influence of hydrocarbon exposure on the course of glomerulonephritis. Nephron 1986; 42: 156-160.

9. Ravnskov U: Hydrocarbons may worsen renal function in glomerulonephritis: a meta-analysis of the case-control studies. Am J Ind Med 2000; 37: 599-606.

10. Ishola AD, Arogundade AF, Sanusi AA, Akinsola A: Association of hydrocarbon exposure with glomerulonephritis in nigerians: a case control study. Saudi J Kidney Dis Transpl 2006; 17: 82-89.

11. Patrick-Iwuanyanwu KC, Onyemaenu CC, Wegwu MO, Ayalogu EO: Hepatotoxic and nephrotoxic effects of kerosene and petrol-contaminated diets in Wistar albino rats. Res J Environ Toxicol 2011; 5: 49-57.

\section{Conclusions}

Exposure to toxicants of petroleum origin has the potential of inducing nephrotoxicity, as confirmed by our findings. It could be regarded as a risk factor for the development of kidney diseases, therefore it should be considered in the evaluation of patients with kidney diseases in Nigeria. Given the increasing prevalence of kidney diseases in Nigeria and the enormous cost of management, all efforts should be made to prevent it. The need for a non-invasive, reliable, cheap and easily available tool for diagnosing petroleum product-induced kidney diseases in Nigeria is desirable. This study demonstrated that ultrasound is useful in the evaluation of petroleum-induced nephropathy. Therefore, in addition to biochemical evaluation, imaging should be included as a routine investigative tool in assessing toxicantinduced kidney damage.

\section{Conflict of interest}

Authors do not report any financial or personal connections with other persons or organizations, which might negatively affect the contents of this publication and/or claim authorship rights to this publication.

12. Heynemann H, Tuma J: Renal ultrasound. Urologic and nephrologic viewpoint. Praxis (Bern 1994) 2006; 95: 729-735.

13. Radermacher J: Ultrasonography of the kidney and renal vessels. I. Normal findings, inherited and parenchymal diseases. Urologe A 2005; 44: 1351-1363.

14. Elia M: Nutrition. In: Kumar P and Clark M (eds.): Clinical Medicine. Elsevier Saunders, Edinburgh 2005: 255-263.

15. Onwubere BJC: Essentials of hypertension management. Institute of Development Studies UNEC Enugu 2005: 3.

16. Gale EAM, Anderson JVA: Diabetes mellitus and other disorders of metabolism. In: Kumar P, Clark M (eds.): Clinical Medicine. Elsevier Saunders, Edinburgh 2005: 1101-1151.

17. Sanders RC, Miner NS: Right upper quadrant mass. In: Clinical Sonography: A Practical Guide. Little, Brown and Company, Boston/Toronto/ London 1991: 213-239.

18. Palmer P: Manual of diagnostic ultrasound. World Health Organization, Geneva 1995: 152-155.

19. Porro A, Lomonte C, Coratelli P, Passavanti G, Ferri GM, Assennato G: Chronic glomerulonephritis and exposure to solvents: a case-referent study. Br J Ind Med 1992; 49: 738-742.

20. Pranjić N, Mujagić H, Nurkić M, Karamehić J, Pavlović S: Assessment of health effects in workers at gasoline station. Bosn J Basic Med Sci 2002; 2: 35-45.

21. Anakwue AM, Anakwue R, Okeji M, Idigo F, Agwu K, Nwogu U: Sonographic assessment of petroleum-induced hepatotoxicity in Nigerians:does biochemical assessment undersetimate liver damage? African Health Sciences 2017; 17: 270-277.

22. Nwanjo HU, Ojiako OA: Investigation of the potential health hazards of petrol station attendants in Owerri Nigeria. J Appl Sci Environ Manage 2007; 11: 197-200. 
23. Bartimaeus ES, Jacobs MJ: The effect of exposure to petroleum products on some renal function parameters of motor mechanics in Port Harcourt Metropolis of Nigeria. GJPAS 2003; 9: 59-63.
24. Momoh J, Oshin TT: Severe hepatotoxicity and nephrotoxicity of gasoline (petrol) on some biochemical parameters in Wistar male albino rats. Am J Biochem 2015; 5: 6-14. 